\title{
PENGARUH PENGUNAAN ALAT PERAGA TERHADAP HASIL BELAJAR MURID DALAM PROSES PEMBELAJARAN BIDANG STUDI IPA KELAS IV SDN LIMBUNG PUTERI KECAMATAN BAJENG KABUPATEN GOWA
}

\author{
Wahyuni, Khaeruddin, Irmawanty. \\ Pendidikan Guru Sekolah Dasar, Fakultas Keguruan dan Ilmu Pendidikan \\ Universitas Muhammadiyah Makassar \\ Iqramsyar34@gmail.com
}

\begin{abstract}
ABSTRAK
Masalah utama dalam penelitian ini yaitu apakah tedapat pengaruh penggunaan alat peraga terhadap hasil belajar murid bidang studi IPA kelas IV SDN Limbung Puteri Kecamatan Bajeng Kabupaten Gowa. Penelitian ini bertujuan untuk mengetahui pengaruh penggunaan alat peraga dalam proses pembelajaran bidang studi IPA kelas IV SDN Limbung Puteri Kecamatan Bajeng Kabupaten Gowa. Jenis penelitian ini adalah penelitian pra-eksperimen bentuk Pretest Posttest Design yaitu sebuah eksperimen yang dalam pelaksanaannya hanya melibatkan satu kelas sebagai kelas eksperimen tanpa adanya kelas pembanding (kelas kontrol) yang bertujuan untuk mengetahui pengaruh penggunaan alat peraga teradap hasil belajar murid dalam proses pembelajaran bidang studi IPA kelas IV SDN Limbung Puteri Kecamatan Bajeng Kabupaten Gowa tahun ajaran 2016/2017. Satuan eksperimen dalam penelitian ini adalah murid Kelas IV sebanyak 28 orang. Penelitian dilaksanakan selama 6 kali pertemuan. Keberhasilan proses pembelajaran ditinjau dari aspek, yaitu: ketercapaian ketuntasan hasil belajar IPA murid secara klasikal dan aktivitas murid dalam pembelajaran IPA. Pembelajaran dikatakan berhasil jika aspek di atas terpenuhi. Teknik pengumpulan data yang digunakan adalah data hasil belajar IPA murid yang dikumpulkan dengan menggunakan tes hasil belajar, data tentang aktivitas murid dalam pembelajaran IPA dikumpulkan dengan menggunakan lembar observasi aktivitas belajar murid. Hasil analisis statistik deskriptif terhadap hasil belajar murid terhadap alat peragat positif, pemahaman materi dan konsep dari IPA dengan media pembelajaran alat peraga ini menunjukkan hasil belajar yang lebih baik dari pada sebelum menggunakan alat peraga. Hasil analisis statistik inferensial menggunakan rumus uji-t, diketahui bahwa nilai $\mathrm{t}$ Hitung yang diperoleh adalah 8,32 dengan frekuensi $\mathrm{dk}=28$ $-1=27$, pada taraf signifikansi $5 \%$ diperoleh $\mathrm{t}_{\text {Tabel }}=0,381$. Jadi, $\mathrm{t}_{\text {Hitung }}>\mathrm{t}_{\text {tabel }}$ atau hipotesis nol $\left(\mathrm{H}_{0}\right)$ ditolak dan hipotesis alternative $\left(\mathrm{H}_{\mathrm{a}}\right)$ diterima. Hal ini membuktikan bahwa penggunaan alat peraga dalam pembelajaran IPA mempunyai pengaruh dari pada sebelum menggunakan media pembelajaran alat peraga.
\end{abstract}

Kata kunci: Pra eksperimen; alat peraga; hasil belajar. 


\section{PENDAHULUAN}

Untuk mencapai tujuan pendidikan tersebut kita harus berpatokan pada standar pendidikan.Dimana, ada delapan standar pendidikan yaitu standar proses, standar isi, standar kompetensi lulusan, standar sarana dan prasarana, standar sarana pendidik dan tenaga kependidikan, standar pembiayaan, standar pengelolaan, dan standar penilaian. Namun, yang menjadi fokus utama adalah standar isi yang mencakup lingkup materi dan tingkat kompetensi. Adapun salah satu kompetensi yang harus dikembangkan dalam pendidikan adalah kompetensi kreatifitas.

Pada kenyataannya, di zaman yang semakin berkembang sekarang ini kompetensi kreatifitas sangat dibutuhkan dalam menghadapi masa depan dan era globalisasi serta canggihnya TIK yang berkembang pesat. Demikian pula dalam kehidupan sehari-hari setiap orang selalu dihadapkan pada berbagai masalah yang harus dipecahkan dan menuntut kreatifitas untuk merumuskan solusinya.Untuk mengembangkan kreatifitas murid, salah satunya adalah pembelajaran IPA. Dalam hal ini dapat ditemukan bahwa pada proses pembelajaran IPA, murid memperoleh latihan secara implisit maupun secara ekplisitcara berpikir kreatif dalam memecahkan masalah. Bahkan dengan jelas dikemukakan dalam KBK dikdas IPA 2004 bahwa salah satu tujuan pembelajaran IPA yang hendak dicapai adalah untuk menjadikan murid mempunyai pandangan yang lebih luas serta memiliki sikap menghargai, tekun, sikap kritis, objektif, terbuka, inovatif dan kreatif, membantu murid mengembangkan daya nalar, berpikir logis, sistematika logis, kreatif, cerdas, rasa keindahan, sikap terbuka dan rasa ingin tahu, mawas diri, mandiri, bekerjasama, dan bertanggung jawab.

Mengingat tuntutan terhadap penguasaan materi di kelas IV SD semester 2, dan agar tujuan pembelajaran Ilmu Pengetahuan Alam (IPA) dapat tercapai secara optimal, maka dalam penyajian materi, guru hendaknya memberi kesempatan kepada murid untuk mengembangkan segala potensinya, membangun sendiri pengetahuannya untuk memecahkan masalah serta membuat pembelajaran lebih bermakna. Pernyataan tersebut berdasarkan atas pendapat Piaget (Dahar, 1996:117) yang menyatakan bahwa pengetahuan itu dibangun dalam pikiran anak.

Kenyataan di lapangan, peneliti memperoleh temuan mengenai sikap murid terhadap proses pembelajaran Ilmu Pengetahuan Alam (IPA), murid mengalami kejenuhan karena pembelajaran kurang menarik, guru kurang memberikan kesempatan kepada murid untuk aktif memanipulasikan benda-benda secara 
langsung, sehingga sebagian besar murid sukar memahami setiap konsep yang diajarkan, yang akhirnya prestasi belajar murid menjadi rendah.

Untuk itu diperlukan metode yang dapat membuat murid lebih aktif dalam pembelajaran.Adapun metode yang digunakan adalah metode pengguaan alat peraga.Dimana metode ini merupakan metode untuk mengukur kekreatifan anak dalam menangkap mata pelajaran yang diajarkan oleh seorang guru, selain itu metode ini juga bertujuan agar murid berpikir dan memiliki wawasan yang luas. Dengan demikian jiwa kreatif anak, khususnya dalam pembelajaran IPA akan meningkat. Sehingga hasil belajar pun akan meningkat.

Berdasarkan uraian di atas rumusan masalah dalam penelitian ini adalah: :"Apakah terdapat pengaruh penggunaan Alat Peraga terhadap Hasil Belajar Murid bidang Studi IPA kelas IV di SDN Limbung Puteri Kecamatan Bajeng Kabupaten Gowa ?". Tujuan penelitian ini adalah mengetahui: adalahUntuk mengetahui pengaruh penggunaan Alat Peraga dalam proses pembelajaran bidang Studi IPA kelas IV di SDN Limbung Puteri Kecamatan Bajeng Kabupaten Gowa.

\section{Hasil Belajar}

Menurut Burton, dalam sebuah buku "The Guidance of Learning Activities" dalam Aunurrahman (2009:35-38) merumuskan pengertian belajar sebagai perubahan tingkah laku pada diri individu berkat adanya interaksi antara individu dengan individu dan individu dengan lingkungannya. Abdillah (2002) mengidentifikasikan sejumlah pengertian belajar yang bersumber dari para ahli pendidikan/pembelajaran. Belajar adalah suatu proses yang dilakukan individu untuk memperoleh suatu perubahan tingkah laku yang baru secara keseluruhan, sebagai hasil pengalaman individu itu sendiri di dalam interaksi dengan lingkungannya.

Jika kita simpulkan dari sejumlah pandangan dan definisi tentang belajar (Wragg, 1994), kita menemukan ciri umum kegiatan belajar sebagai berikut :

1) Belajar menunjukkan suatu aktivitas pada diri seseorang yang disadari atau disengaja.

2) Belajar merupakan interaksi individu dengan lingkungannya.

3) Hasil belajar ditandai dengan perubahan tingkah laku.

Menurut Suprijono (2009: 5) "hasil belajar adalah pola-pola perbuatan, nilainilai, pengertian-pengertian, sikap-sikap, apresiasi dan keterampilan-keterampilan". Sedangkan menurut Gagne (dalam Suprijono, 2009:5) hasil belajar berupa: (1) 
Informasi verbal yaitu kapabilitas mengungkapkan pengetahuan dalam bentuk bahasa, baik lisan maupun tertulis. (2) Keterampilan intelektual (3) Strategi kognitif dalam memecahkan masalah. (4) Ketarampilan motorik (5) Sikap.

Selanjutnya menurut Bloom (dalam Suprijono, 2009:6) hasil belajar mencakup: kemampuan kognitif, efektif, dan psikomotorik.

1. Domain kognitif:knowledge(pengetahuan, ingatan), comprehension (pemahaman, menjelaskan,meringkas), application (menerapkan), analysis (mengorganisasikan, merencanakan), dan evaluation (menilai).

2. Domain efektif: receiving (sikap menerima), responding (memberikan respons), valuing (nilai), organization (organisasi), characterization (karakterisasi).

3. Psikomotorik mencakup keterampilan produktif, teknik, fisik, sosial, manajerial, dan intelektual.

Berdasarkan uraian di atas dapat disimpulkan bahwa, hasil belajar adalah perubahan prilaku secara keseluruhan bukan hanya satu aspek potensi kemanusiaan saja.

\section{Pengertian IPA}

Menurut Asih (2013 : 23) mengemukakan bahwa ada tiga istilah yang terlibat dalam hal ini, yaitu "ilmu”, " pengetahuan", dan "alam". Pengetahuan adalah segala sesuatu diketahui manusia.Dalam hidupnya, banyak sekali pengetahuan yang dimiliki manusia.Pengetahuan tentang agama, pendidikan, kesehatan, ekonomi, politik, sosial, dan alam sekitar adalah contoh pengetahuan yang dimiliki manusia.Pengetahuan alam berarti pengetahuan tentang alam semesta beserta isinya.

Ilmu adalah pengetahuan yang ilmiah, pengetahuan yang diperoleh secara ilmiah, artinya diperoleh dengan metode ilmiah.Dua sifat utama ilmu adalah rasional, artinya masuk akal, logis, atau dapat diterima akal sehat, dan objektif.Artinya, sesuai dengan objeknya, sesuai dengan kenyataannya, atau sesuai dengan pengamatan. Dengan pengertian ini, IPA dapat diartikan sebagai ilmu yang mempelajari tentang sebab dan akibat kejadian-kejadian yang ada di alamini (soekarno,1973) dalam Asih (2013: 23).

\section{Alat Peraga /Media Pembelajaran}

Alat peraga disamakan dengan media. Kata media berasal dari bahasa latin medium yang secara harfiah berarti "tengah" perantara.."Dalam aktivitas pembelajaran, media dapat didefinisikan sebagai sesuatu yang dapat membawa 
informasi dan pengetahuan dalam interaksi yang berlangsung antara pendidik dengan peserta didik"(Arsyad, 2013: 3).

Simak Y dan Syafei, 2012 mengemukakan bahwa: Alat peraga ialah alat-alat yang digunakan guru yang berfungsi membantu guru dalam proses mengajarnya dan membantu peserta didik dalam proses belajarnya (Arsyad, 2013: 10).

Masih dalam hubungan dengan media pembelajaran, Santoso S. Hamidjojo mengatakan bahwa Media pembelajaran adalah media yang penggunaannya diintegrasikan dengan tujuan dan isi pengajaran biasanya sudah dituangkan dalam mempertinggi mutu kegiatan belajar-mengajar (Latuheru, 2002 : 16-17).

Alat Peraga/media pembelajaran merupakan sarana untuk meningkatkan pemahaman murid terhadap materi pelajaran. Alat peraga/media pembelajaran mengandung dua unsur yaitu: (1) pesan atau bahan pembelajaran yang akan disampaikan atau disebut juga solftware, dan (2) alat penunjang atau hardware. Seringkali orang menyebut media sebagai alat bantu pengajaran, tetapi media pembelajaran dapat dibedakan dari alat bantu pengajaran dalam hal fungsinya. Alat bantu mengajar bukanlah bagian integral dari kegiatan pembelajaran tetapi hanya membantu meningkatkan efisiensi pembelajaran.

Jadi dapat diambil kesimpulan di sini bahwa media pembelajaran (alat peraga) adalah semua alat bantu atau benda yang digunakan dalam kegiatan belajar-mengajar, dengan maksud untuk menyampaikan pesan (informasi) pembelajaran dari sumber (guru maupun sumber lain) kepada penerima (dalam hal ini perserta didik), dengan menggunakan alat indera mereka. Lebih lanjut dari itu lebih baik lagi jika seluruh alat indera yang dimiliki mampu/dapat menerima pesan yang disampaikan.

\section{METODE PENELITIAN}

Jenis penelitian yang digunakan adalah penelitian pra- eksperimen atau preexperiment yaitu rancangan penelitian eksperimen yang hanya menggunakan kelompok eksperimen saja, tanpa kelompok kontrol (pembanding) sampel subyek dipilih seadanya tanpa mempergunakan randomisasi. Rancangan yang digunakan adalah "One Group Pretest-Postest Design"

Populasi dalam penelitian ini adalah seluruh murid SDN Limbung Puteri dengan jumlah keseluruhan murid adalah 391 murid. sampel pada penelitian ini adalah semua murid kelas IV A SDN Limbung Puteri Kecamatan Bajeng Kabupaten 
Gowa yang berjumlah 28 murid. Untuk menganalisis data yang diperoleh dari hasil penelitian akan digunakan analisis regresi linier sederhana, analisis statistik deskriptif dan analisis statistik inferensial.

\section{HASIL PENELITIAN DAN PEMBAHASAN}

Deskripsi Hasil Pretest sebelum Menggunakan Alat Peraga terhadap Hasil Belajar Murid dalam proses pembelajaran bidang studi IPA Kelas IV SDN Limbung Puteri Kecamatan Bajeng Kabupaten Gowa

Data hasil belajar murid kelas IV SDN Limbung Puteri Kecamatan Bajeng Kabupaten Gowa dapat diketahui sebagai berikut :

Tabel 4.1. Skor Nilai Pretest

\begin{tabular}{|c|c|c|}
\hline No & Nama Murid & Nilai \\
\hline 1 & Afifa Khairun Niswa & 50 \\
\hline 2 & St. Nadira Fairuzia & 40 \\
\hline 3 & St. Nadila Fairuzia & 60 \\
\hline 4 & Muh. Nur Alfiansyah & 60 \\
\hline 5 & Husnul Muflihah & 70 \\
\hline 6 & Siska Arya Ningsih & 40 \\
\hline 7 & Muh. Hafidz & 70 \\
\hline 8 & Muh. Raihan febrian & 60 \\
\hline 9 & Ainul Burhani & 55 \\
\hline 10 & Dilsa Alani Arman & 60 \\
\hline 11 & Oya Salfitra Mulfa & 40 \\
\hline 12 & Ibrahim & 40 \\
\hline 13 & Hazarika Iffihani R & 70 \\
\hline 14 & Naurah Alkhalisa & 60 \\
\hline 15 & Nayla Fairuzia & 60 \\
\hline 16 & Sri Nabila Aqsa & 60 \\
\hline 17 & Rainy Husna Mannaba & 60 \\
\hline 18 & Rifqah Naila M & 60 \\
\hline 19 & Muh Fadil Maulama & 70 \\
\hline
\end{tabular}




\begin{tabular}{|c|l|c|}
\hline 20 & Syifa Anada Zakaria & 60 \\
\hline 21 & Muh Khalif Dafairzi & 40 \\
\hline 22 & Danas tasya ananda syarman & 60 \\
\hline 23 & Alfatun Nisa & 40 \\
\hline 24 & Muh. Djibril Risyak Cisse & 50 \\
\hline 25 & Washiyatul akmal & 60 \\
\hline 26 & Nabilah nur zaimah akhsan & 70 \\
\hline 27 & Ahmad Satria Abdillah & 60 \\
\hline 28 & Rasya islamay pasha & 50 \\
\hline
\end{tabular}

Untuk mencari mean (rata-rata) nilai pretest dari murid kelas IV SDN Limbung Puteri Kecamatan Bajeng Kabupaten Gowa dapat dilihat melalui tabel di bawah ini :

Tabel 4.2. Perhitungan untuk mencari mean ( rata - rata ) nilai pretest

\begin{tabular}{|c|c|c|}
\hline $\mathbf{X}$ & $\mathbf{F}$ & $\mathbf{F . X}$ \\
\hline 40 & 5 & 200 \\
\hline 50 & 3 & 150 \\
\hline 55 & 1 & 55 \\
\hline 60 & 13 & 780 \\
\hline 70 & 6 & 420 \\
\hline Jumlah & $\mathbf{2 8}$ & $\mathbf{1 6 0 5}$ \\
\hline
\end{tabular}

Dari data di atas dapat diketahui bahwa nilai dari $\sum f x=1605$, sedangkan nilai dari $\mathrm{N}$ sendiri adalah 28. Oleh karena itu dapat diperoleh nilai rata-rata (mean) sebagai berikut :

$$
\begin{aligned}
\bar{x} & =\frac{\sum_{i=1}^{k} f x_{i}}{n} \\
& =\frac{1605}{28} \\
& =57,3
\end{aligned}
$$

Dari hasil perhitungan di atas maka diperoleh nilai rata-rata dari hasil belajar kelas IV SDN Limbung Puteri Kecamatan Bajeng Kabupaten Gowa sebelum menggunakan Alat Peraga yaitu 57,3. Adapun dikategorikan pada pedoman 
Departemen pendidikan dan kebudayaan (Depdikbud), maka keterangan murid dapat dilihat pada tabel berikut :

Tabel 4.3. Tingkat Penguasaan Materi Pretest

\begin{tabular}{|c|c|c|c|c|}
\hline No. & Interval & Frekuensi & $\begin{array}{c}\text { Persentase } \\
\mathbf{( \% )}\end{array}$ & $\begin{array}{c}\text { Kategori hasil } \\
\text { belajar }\end{array}$ \\
\hline 1. & $0-54$ & 8 & $28,6 \%$ & Sangat rendah \\
\hline 2. & $55-64$ & 14 & $50 \%$ & Rendah \\
\hline 3. & $65-79$ & 6 & $21,4 \%$ & Sedang \\
\hline 4. & $80-89$ & 0 & $0 \%$ & Tinggi \\
\hline 5. & $90-100$ & 0 & $0 \%$ & Sangat Tinggi \\
\hline \multicolumn{2}{|c|}{ Jumlah } & $\mathbf{2 8}$ & $\mathbf{1 0 0 \%}$ & \\
\hline
\end{tabular}

Berdasarkan data yang dapat dilihat pada tabel di atas maka dapat disimpulkan bahwa hasil belajar murid pada tahap pretest dengan menggunakan instrumen test dikategorikan sangat rendah yaitu 28,6\%, rendah 50\%, sedang 21,4\%, tinggi $0 \%$ dan sangat tingggi berada pada presentase $0 \%$. Melihat dari hasil presentase yang ada dapat dikatakan bahwa tingkat kemampuan murid dalam memahami serta penguasaan materi pelajaran matematika sebelum menggunakan Alat Peraga tergolong sedang.

Tabel 4.4 Deskripsi Ketuntasan Hasil Belajar IPA

\begin{tabular}{|c|c|c|c|}
\hline Skor & Kategorisasi & Frekuensi & $\begin{array}{c}\text { Persentase } \\
\text { (\%) }\end{array}$ \\
\hline $0 \leq \times<65$ & Tidak tuntas & 22 & $78,6 \%$ \\
\hline $65 \leq \times \leq 100$ & Tuntas & 6 & $21,4 \%$ \\
\hline \multicolumn{2}{|c|}{ Jumlah } & $\mathbf{2 8}$ & $\mathbf{1 0 0 \%}$ \\
\hline
\end{tabular}

Apabila Tabel 4.4 dikaitkan dengan indikator kriteria ketuntasan hasil belajar murid yang ditentukan oleh peneliti yaitu jika jumlah murid yang mencapai atau melebihi nilai KKM (65) $\geq 75 \%$, sehingga dapat disimpulkan bahwa hasil belajar IPA kelas IV SDN Limbung Puteri Kecamatan Bajeng Kabupaten Gowa belum memenuhi kriteria ketuntasan hasil belajar secara klasikal dimana murid yang tuntas hanya $21,4 \% \leq 75 \%$. 
Deskripsi Hasil Belajar (posttest) setelah Menggunakan Alat Peraga terhadap Hasil Belajar Murid dalam proses pembelajaran bidang studi IPA Kelas IV SDN Limbung Puteri Kecamatan Bajeng Kabupaten Gowa

Selama penelitian berlangsung terjadi perubahan terhadap kelas setelah diberikan perlakuan. Perubahan tersebut berupa hasil belajar yang datanya diperoleh setelah diberikan posttest. Perubahan tersebut dapat dilihat dari data hasil belajar IPA kelas IV SDN Limbung Puteri Kecamatan Bajeng Kabupaten Gowa setelah menggunakan Alat Peraga:

Tabel 4.5. Skor Nilai Posttest

\begin{tabular}{|c|l|c|}
\hline No & \multicolumn{1}{|c|}{ Nama Murid } & Nilai \\
\hline 1 & Afifa Khairun Niswa & 90 \\
\hline 2 & St. Nadira Fairuzia & 100 \\
\hline 3 & St. Nadila Fairuzia & 80 \\
\hline 4 & Muh. Nur Alfiansyah & 90 \\
\hline 5 & Husnul Muflihah & 90 \\
\hline 6 & Siska Arya Ningsih & 100 \\
\hline 7 & Muh. Hafidz & 75 \\
\hline 8 & Muh. Raihan febrian & 90 \\
\hline 9 & Ainul Burhani & 90 \\
\hline 10 & Dilsa Alani Arman & 60 \\
\hline 11 & Oya Salfitra Mulfa & 80 \\
\hline 12 & Ibrahim & 90 \\
\hline 13 & Hazarika Iffihani R & 70 \\
\hline 14 & Naurah Alkhalisa & 90 \\
\hline 15 & Nayla Fairuzia & 85 \\
\hline 16 & Sri Nabila Aqsa & 85 \\
\hline 17 & Rainy Husna Mannaba & 100 \\
\hline 18 & Rifqah Naila M & 80 \\
\hline 19 & Muh Fadil Maulama & 75 \\
\hline 20 & Syifa Anada Zakaria & 80 \\
\hline 21 & Muh Khalif Dafairzi & \\
\hline 22 & Danas tasya ananda syarman & 85 \\
\hline & & \\
\hline
\end{tabular}




\begin{tabular}{|c|l|c|}
\hline 23 & Alfatun Nisa & 80 \\
\hline 24 & Muh. Djibril Risyak Cisse & 80 \\
\hline 25 & Washiyatul akmal & 85 \\
\hline 26 & Nabilah nur zaimah akhsan & 85 \\
\hline 27 & Ahmad Satria Abdillah & 60 \\
\hline 28 & Rasya islamay pasha & 75 \\
\hline
\end{tabular}

Untuk mencari mean (rata-rata) nilai posttest dari kelas IV SDN Limbung Puteri Kecamatan Bajeng Kabupaten Gowa.

Tabel 4.6. Perhitungan untuk mencari mean (rata-rata) nilai posttest

\begin{tabular}{|c|c|c|}
\hline $\mathbf{X}$ & $\mathbf{F}$ & F.X \\
\hline 60 & 2 & 120 \\
\hline 70 & 1 & 70 \\
\hline 75 & 3 & 225 \\
\hline 80 & 6 & 480 \\
\hline 85 & 6 & 510 \\
\hline 90 & 7 & 630 \\
\hline $\mathbf{1 0 0}$ & 3 & 300 \\
\hline Jumlah & $\mathbf{2 8}$ & $\mathbf{2 3 3 5}$ \\
\hline
\end{tabular}

Dari data hasil post-test di atas dapat diketahui bahwa nilai dari $\sum f x=2335$ dan nilai dari $\mathrm{N}$ sendiri adalah 28. Kemudian dapat diperoleh nilai rata-rata (mean) sebagai berikut :

$$
\begin{aligned}
\bar{x} & =\frac{\sum_{i=1}^{k} f x_{i}}{n} \\
& =\frac{2335}{28} \\
& =83,4
\end{aligned}
$$

Dari hasil perhitungan di atas maka diperoleh nilai rata-rata dari hasil belajar murid kelas IV SDN Limbung Puteri Kecamatan Bajeng Kabupaten Gowa setelah menggunakan Alat Peraga yaitu 83,4 dari skor ideal 100. 
Adapun di kategorikan pada pedoman Departemen pendidikan dan kebudayaan (Depdikbud), maka keterangan murid dapat dilihat pada tabel berikut:

Tabel 4.7. Tingkat Penguasaan Materi Post-test

\begin{tabular}{|c|c|c|c|c|}
\hline No. & Interval & Frekuensi & $\begin{array}{c}\text { Persentase } \\
\mathbf{( \% )}\end{array}$ & $\begin{array}{c}\text { Kategori hasil } \\
\text { belajar }\end{array}$ \\
\hline 1. & $0-54$ & 0 & $0 \%$ & Sangat rendah \\
\hline 2. & $55-64$ & 2 & $7,14 \%$ & Rendah \\
\hline 3. & $65-79$ & 4 & $14,3 \%$ & Sedang \\
\hline 4. & $80-89$ & 12 & $42,85 \%$ & Tinggi \\
\hline 5. & $90-100$ & 10 & $35,71 \%$ & Sangat Tinggi \\
\hline \multicolumn{2}{|c|}{ Jumlah } & $\mathbf{2 8}$ & $\mathbf{1 0 0 \%}$ & \\
\hline
\end{tabular}

Berdasarkan data yang dapat dilihat pada tabel di atas maka dapat disimpulkan bahwa hasil belajar pada tahap posttest dengan menggunakan instrumen test dikategorikan sangat tinggi yaitu 35,71\%, tinggi 42,85\%, sedang 14,3\%, rendah $7,14 \%$, dan sangat rendah berada pada presentase $0 \%$. Melihat dari hasil presentase yang ada dapat dikatakan bahwa tingkat kemampuan murid dalam memahami serta penguasaan materi pelajaran IPA setelah menggunakan Alat Peraga tergolong tinggi.

Tabel 4.8 Deskripsi Ketuntasan Hasil Belajar IPA

\begin{tabular}{|c|c|c|c|}
\hline Skor & Kategorisasi & Frekuensi & $\begin{array}{l}\text { Persentase } \\
(\%)\end{array}$ \\
\hline $0 \leq x<65$ & Tidak tuntas & 2 & $7,17 \%$ \\
\hline $65 \leq x \leq 100$ & Tuntas & 26 & $92,85 \%$ \\
\hline \multicolumn{2}{|c|}{ Jumlah } & 28 & $100 \%$ \\
\hline
\end{tabular}

Apabila Tabel 4.8 dikaitkan dengan indikator kriteria ketuntasan hasil belajar murid yang ditentukan oleh peneliti yaitu jika jumlah murid yang mencapai atau melebihi nilai KKM (65) $\geq 75 \%$, sehingga dapat disimpulkan bahwa hasil belajar IPA Kelas IV SDN Limbung Puteri Kecamatan Bajeng Kabupaten Gowa telah memenuhi kriteria ketuntasan hasil belajar secara klasikal dimana murid yang tuntas adalah $92,85 \% \geq 75 \%$. 


\section{Deskripsi Aktivitas Belajar selama Menggunakan Alat Peraga terhadap}

Hasil Belajar Murid dalam proses pembelajaran bidang studi IPAKelas IV SDN Limbung Puteri Kecamatan Bajeng Kabupaten Gowa

Hasil pengamatan aktivitas murid dalam mengikuti pembelajaran dengan menggunakan Alat Peraga selama 3 kali pertemuan dinyatakan dalam persentase sebagai berikut:

Tabel 4.9 Hasil Analisis Data Observasi Aktivitas Murid

\begin{tabular}{|c|c|c|c|c|c|c|c|c|c|c|c|c|}
\hline \multirow[t]{2}{*}{ No } & \multirow{2}{*}{ Aktivitas Murid } & \multicolumn{8}{|c|}{$\begin{array}{l}\text { Jumlah Murid yang Aktif pada } \\
\text { Pertemuan ke- }\end{array}$} & $\begin{array}{l}\text { Rata- } \\
\text { rata }\end{array}$ & $\%$ & $\begin{array}{c}\text { Kateg } \\
\text { ori }\end{array}$ \\
\hline & & 1 & 2 & 3 & 4 & 5 & 6 & 7 & 8 & & & \\
\hline 1. & $\begin{array}{l}\text { Murid yang hadir } \\
\text { pada saat } \\
\text { pembelajaran }\end{array}$ & $P$ & 28 & 28 & 28 & 28 & 28 & 28 & $P$ & 28 & 100 & Aktif \\
\hline 2. & $\begin{array}{l}\text { Murid yang } \\
\text { berpatisipasi dalam } \\
\text { kelompoknya }\end{array}$ & 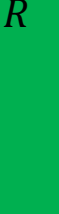 & 16 & 17 & 17 & 18 & 16 & 18 & 0 & 17 & 60,71 & Aktif \\
\hline 3. & $\begin{array}{l}\text { Murid yang } \\
\text { menghubungkan } \\
\text { pengetahuan yang } \\
\text { dimilikinya. }\end{array}$ & $T$ & 15 & 19 & 17 & 16 & 15 & 17 & $T$ & 16,5 & 58,92 & Aktif \\
\hline 4. & $\begin{array}{l}\text { Murid yang antusias } \\
\text { memprediksi judul }\end{array}$ & $E$ & 15 & 16 & 16 & 18 & 15 & 17 & $T$ & 16,15 & 67,70 & Aktif \\
\hline 5. & $\begin{array}{l}\text { Murid yang akktif } \\
\text { mengikuti } \\
\text { bimbingan guru }\end{array}$ & $S$ & 20 & 17 & 14 & 17 & 13 & 16 & $E$ & 16,16 & 80,95 & Aktif \\
\hline 6. & $\begin{array}{l}\text { Murid yang aktif } \\
\text { memprediksi } \\
\text { jawaban }\end{array}$ & $T$ & 14 & 12 & 17 & 18 & 17 & 16 & $S$ & 13,16 & 73,83 & Aktif \\
\hline
\end{tabular}




\begin{tabular}{|c|c|c|c|c|c|c|c|c|c|c|}
\hline 7 & $\begin{array}{l}\text { Murid yang aktif } \\
\text { membuat ringkasan } \\
\text { singkat bacaan }\end{array}$ & 16 & 15 & 17 & 17 & 14 & 17 & 17,16 & 77,38 & Aktif \\
\hline 8 & $\begin{array}{l}\text { Murid yang } \\
\text { menghadirkan } \\
\text { pengalaman belajar } \\
\text { yang dilalui }\end{array}$ & 13 & 14 & 16 & 18 & 17 & 16 & 15,83 & 72,61 & Aktif \\
\hline 9 & $\begin{array}{l}\text { Murid yang } \\
\text { melakukan hasil } \\
\text { sering dan diskusi }\end{array}$ & 14 & 12 & 11 & 16 & 16 & 17 & 14,33 & 63,09 & Aktif \\
\hline 10 & $\begin{array}{l}\text { Murid yang aktif } \\
\text { mencari ide pokok }\end{array}$ & 15 & 18 & 16 & 16 & 17 & 16 & 13,66 & 67,70 & Aktif \\
\hline 11 & $\begin{array}{l}\text { Murid yang Aktif } \\
\text { mengenal kesalahan } \\
\text { dan menarik } \\
\text { kesimpulan }\end{array}$ & 15 & 17 & 16 & 19 & 17 & 18 & 17 & 79,76 & Aktif \\
\hline & Rata-rata & & & & & & & & & Aktif \\
\hline
\end{tabular}

Pengaruh Penggunaan Alat Peraga terhadap Hasil Belajar Murid dalam proses pembelajaran bidang studi IPA Kelas IV SDN Limbung Puteri Kecamatan Bajeng Kabupaten Gowa

Sesuai dengan hipotesis penelitian yakni "penggunaan Alat Peraga memiliki pengaruh terhadap hasil belajar IPA kelas IV SDN Limbung Puteri Kecamatan Bajeng Kabupaten Gowa", maka teknik yang digunakan untuk menguji hipotesis tersebut adalah teknik statistik inferensial dengan menggunakan uji-t.

Tabel 4.10. Analisis skor Pretest dan Posttest

\begin{tabular}{|c|c|c|c|c|}
\hline No. & $\begin{array}{c}\mathrm{X} 1 \\
(\text { Pretest })\end{array}$ & $\begin{array}{c}\mathrm{X} 2 \\
\text { (Posttest })\end{array}$ & $\mathrm{d}=\mathrm{X} 2-\mathrm{X} 1$ & $\mathrm{~d}^{2}$ \\
\hline
\end{tabular}




\begin{tabular}{|c|c|c|c|c|}
\hline 1. & 50 & 90 & 40 & 1600 \\
\hline 2. & 40 & 100 & 60 & 3600 \\
\hline 3. & 60 & 80 & 20 & 400 \\
\hline 4. & 60 & 90 & 30 & 900 \\
\hline 5. & 70 & 90 & 20 & 400 \\
\hline 6. & 40 & 100 & 60 & 3600 \\
\hline 7. & 70 & 75 & 5 & 25 \\
\hline 8. & 60 & 90 & 30 & 900 \\
\hline 9. & 55 & 90 & 35 & 1225 \\
\hline 10. & 60 & 60 & 0 & 0 \\
\hline 11. & 40 & 80 & 40 & 1600 \\
\hline 12. & 40 & 90 & 50 & 2500 \\
\hline 13. & 70 & 70 & 0 & 0 \\
\hline 14. & 60 & 90 & 30 & 900 \\
\hline 15. & 60 & 85 & 25 & 625 \\
\hline 16. & 60 & 85 & 25 & 625 \\
\hline 17. & 60 & 100 & 40 & 1600 \\
\hline 18. & 60 & 80 & 20 & 400 \\
\hline 19. & 70 & 75 & 5 & 25 \\
\hline 20. & 60 & 80 & 20 & 400 \\
\hline 21. & 40 & 85 & 15 & 225 \\
\hline 22. & 60 & 85 & 15 & 225 \\
\hline 23. & 40 & 80 & 40 & 1600 \\
\hline 24. & 50 & 80 & 30 & 900 \\
\hline 25. & 60 & 85 & 25 & 625 \\
\hline 26. & 70 & 85 & 15 & 225 \\
\hline 27. & 60 & 60 & 0 & 0 \\
\hline 28. & 50 & 75 & 25 & 625 \\
\hline & Jumlah & & 720 & 25750 \\
\hline
\end{tabular}

Langkah-langkah dalam pengujian hipotesis adalah sebagai berikut :

1. Mencari harga "Md" dengan menggunakan rumus: 


$$
\begin{aligned}
\mathrm{Md} & =\frac{\sum d}{N} \\
& =\frac{720}{28} \\
& =25,71
\end{aligned}
$$

2. Mencari harga " $\sum X^{2} d$ " dengan menggunakan rumus:

$$
\begin{aligned}
\sum X^{2} d & =\sum d^{2}-\frac{\left(\sum d\right)^{2}}{N} \\
& =25750-\frac{(720)^{2}}{28} \\
& =25750-\frac{518400}{28} \\
& =25750-18514,28 \\
= & 7235,72
\end{aligned}
$$

3. Menentukan harga $t_{\text {Hitung }}$

$$
\begin{array}{ll}
\mathrm{t} & =\frac{M d}{\sqrt{\frac{\sum X^{2} d}{N(N-1)}}} \\
\mathrm{t} & =\frac{25,71}{\sqrt{\frac{7235,72}{28(28-1)}}} \\
\mathrm{t} & =\frac{25,71}{\sqrt{\frac{7235,72}{28(27)}}} \\
\mathrm{t} & =\frac{25,71}{\sqrt{\frac{7235,72}{756}}} \\
\mathrm{t} & =\frac{25,71}{\sqrt{9,57}} \\
\mathrm{t} & =\frac{25,71}{3,09} \\
\mathrm{t} & =8,32
\end{array}
$$

4. Menentukan harga $t_{\text {Tabel }}$

Untuk mencari $\mathrm{t}$ Tabel peneliti menggunakan tabel distribusi $\mathrm{t}$ dengan taraf signifikan $\alpha=0,05$ dan $d k=N-1=28-1=27$ maka diperoleh $\mathrm{t}_{0,05}=0,381$.

Setelah diperoleh $\mathrm{t}_{\text {Hitung }}=8,32$ dan $\mathrm{t}_{\text {Tabel }}=0,381$ maka diperoleh $\mathrm{t}_{\text {Hitung }}>\mathrm{t}$ Tabel atau 8,32 > 0,381. Sehingga dapat disimpulkan bahwa $\mathrm{H}_{0}$ ditolak dan $\mathrm{H}_{\mathrm{a}}$ diterima sehimgga didapatkan bahwa penggunaan Alat Peraga berpengaruh terhadap hasil belajar murid.

Alat peraga merupakan media yang membantu pengalaman nyata peserta didik. Sehingga peserta didik dapat memperluas wawasan dan pengalaman yang 
mencerminkan pembelajaran nonverbalistik dan membuat generalisasi yang tepat. Alat Peraga membawa kesegaran dan variasi bagi pengalaman belajar murid dan membuat hasil belajar lebih bermakna bagi berbagai kemampuannya. Dengan Alat Peraga, murid akan lebih aktif dalam pembelajaran. Dalam pelaksanaannya, gaya mengajar guru disesuaikan dengan gaya belajar murid, misalnya belajar sambil bermain sehingga murid dapat menyerap materi pelajaran sesuai dengan gaya belajar masing-masing serta daya serap murid terhadap materi pelajaran dapat dicapai secara maksimal.

Berdasarkan hasil pretest, nilai rata-rata hasil belajar murid 57,3 dengan kategori yakni sangat rendah yaitu 26,6\%, rendah 50\%, sedang 21,4\%, tinggi $0 \%$ dan sangat tingggi berada pada presentase $0 \%$. Melihat dari hasil presentase yang ada dapat dikatakan bahwa tingkat kemampuan murid dalam memahami serta penguasaan materi pelajaran matematika sebelum menggunakan Alat Peraga tergolong rendah

Selanjutnya nilai rata-rata hasil posttest adalah 83,4. Jadi hasil belajar IPA setelah menggunakan alat peraga mempunyai hasil belajar yang lebih baik dibanding dengan sebelum menggunakan alat peraga. Selain itu persentasi kategori hasil belajar IPA murid juga meningkat yakni sangat tinggi yaitu 35,71\%, tinggi 42,85\%, sedang $14,3 \%$, rendah $7,14 \%$, dan sangat rendah berada pada presentase $0 \%$.

Berdasarkan hasil analisis statistik inferensial dengan menggunakan rumus uji-

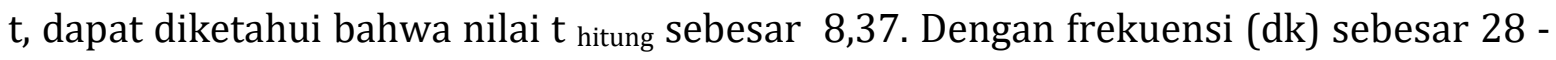
$1=27$, pada taraf signifikansi $5 \%$ diperoleh $t_{\text {tabel }}=0,381$. Oleh karena $t_{\text {hitung }}>t_{\text {tabel }}$ pada taraf signifikansi 0,05 , maka hipotesis nol $\left(\mathrm{H}_{0}\right)$ ditolak dan hipotesis alternative $\left(\mathrm{H}_{\mathrm{a}}\right)$ diterima yang berarti bahwa penggunaan Alat Peraga mempengaruhi hasil belajar IPA.

Hasil analisis diatas yang menunjukkan adanya pengaruh penggunaan alat peraga terhadap hasil belajar IPA, sejalan dengan hasil observasi yang dilakukan. Berdasarkan hasil observasi terdapat perubahan pada murid dimana pada awal kegiatan pembelajaran ada beberapa murid yang melakukan kegiatan lain atau bersikap cuek selama pembelajaran berlangsung. Hal ini dapat dilihat pada pertemuan pertama murid yang melakukan kegiatan lain sebanyak 3 orang, sedangkan pada pertemuan terakhir hanya 2 murid yang melakukan kegiatan lain pada saat guru menjelaskan materi. Pada awal pertemuan, hanya sedikit murid yang aktif pada saat 
pembelajaran berlangsung. Akan tetapi sejalan dengan digunakannya Alat Peraga murid mulai aktif pada setiap pertemuan.

Hasil observasi menunjukkan banyaknya jumlah murid yang menjawab pada saat diajukan pertanyaan dan murid yang mengajukan diri untuk mengerjakan soal di papan tulis. Murid juga mulai aktif dan percaya diri untuk menanggapi jawaban dari murid lain sehingga murid yang lain ikut termotivasi untuk mengikuti pelajaran. Proses pembelajaran yang menyenangkan membuat murid tidak lagi keluar masuk pada saat pembelajaran berlangsung.

Berdasarkan hasil analisis statistik deskriptif dan statistik inferensial yang diperoleh serta hasil observasi yang telah dilakukan, dapat disimpulkan bahwa penggunaan alat peraga memiliki pengaruh terhadap Hasil Belajar Murid dalam proses pembelajaran bidang studi IPA kelas IV SDN Limbung Puteri Kecamatan Bajeng Kabupaten Gowa.

\section{SIMPULAN DAN SARAN}

Simpulan yang lebih rinci terkait pelaksanaan pembelajaran IPA dengan menggunakan alat peraga di kelas IV SDN Limbung Puteri Kecamatan Bajeng Kabupaten Gowa sebagai berikut:

1. Berdasarkan data yang diperoleh dapat disimpulkan bahwa secara umum hasil belajar IPA murid kelas IV SDN Limbung Puteri Kecamatan Bajeng Kabupaten Gowa sebelum menggunakan alat peraga dikategorikan rendah. Hal ini ditunjukkan dari perolehan persentase hasil belajar murid yaitu sangat rendah yaitu $28,6 \%$, rendah $50 \%$, sedang $21,4 \%$, tinggi $0 \%$ dan sangat tingggi berada pada presentase $0 \%$.

2. Berdasarkan data yang diperoleh dapat disimpulkan bahwa secara umum alat peraga berpengaruh terhadap hasil belajar IPA dengan menggunakan alat peraga di kelas IV SDN Limbung Puteri Kecamatan Bajeng Kabupaten Gowa dapat dilihat dari perolehan persentase yaitu sangat tinggi $35,71 \%$, tinggi $42,85 \%$, sedang $14,3 \%$, rendah $7,14 \%$, dan sangat rendah berada pada presentase $0 \%$..

3. Berdasarkan uji hipotesis yang telah dilakukan dapat disimpulkan bahwa penggunaan Alat Peraga memiliki pengaruh terhadap hasil belajar IPA dengan menggunakan alat peraga di kelas IV SDN Limbung Puteri Kecamatan Bajeng 
Kabupaten Gowa setelah diperoleh $\mathrm{t}_{\text {Hitung }}=8,37$ dan $\mathrm{t}$ Tabel $=0,381$ maka diperoleh $\mathrm{t}_{\text {Hitung }}>\mathrm{t}_{\text {Tabel }}$ atau 8,37 $>0,381$.

Berdasarkan temuan yang berkaitan dengan hasil penelitian penggunaan alat peraga yang mempengaruhi hasil belajar IPA dengan menggunakan alat peraga di kelas IV SDN Limbung Puteri Kecamatan Bajeng Kabupaten Gowa, maka dikemukakan beberapa saran sebagai berikut :

1. Kepada para pendidik khususnya guru SDN Limbung Puteri, disarankan untuk menggunakan alat peraga dalam pembelajarannya agar dapat membangkitkan minat dan motivasi murid untuk belajar.

2. Kepada Peneliti, diharapkan mampu mengembangkan alat peraga ini pada mata pelajaran lain demi tercapainya tujuan yang diharapkan.

3. Kepada calon Peneliti, sekiranya dapat mengembangkan penggunaan alat peraga ini karena berdasarkan pengalaman saat jalannya penelitian, murid cenderung suka belajar hal-hal baru dan sangat tertarik untuk menerima pelajaran apabila penjelasan materinya disertai alat peraga.

\section{DAFTAR PUSTAKA}

Asri, A. 2015.Laporan Pemantapan Profesi Keguruan SD Inpres Timbuseng.Laporan tidak diterbitkan.Makassar :Unismuh Makassar.

Aunurrahman.2009. Belajar dan Pembelajaran. Bandung :Alfabeta.

Arsyad, A. 2013.Media pembelajaran. Jakarta: Rajawali Pers.

Latuheru, J.D. 2002.Media Pembelajar.Makassar: Makassar State University.

Sadiman, dkk. 2006. Media Pendidikan (Pengertian, Pengembangan dan Pemanfaatannya). Jakarta: PT. Raja Grafindo Persada.

Sugiyono.2015. Metode Penelitian Pendidikan. Bandung :Alfabeta.

Rahayu, S. 2015.Pengaruh Penggunaan Model Pembelajaran Interaktif (Explicit Instruction) Terhadap Hasil Belajar Bahasa Indonesia Murid Kelas V SD Negeri 15 Jawi-Jawi Kecamatan Bantimurung Kabupaten Maros. Skripsi tidak diterbitkan. Makassar : Unismuh Makassar.

Hamid Darmadi. 2013.Metode penelitian pendidikan dan sosial.Bandung :Alfabeta.

Tripalupi, L. E. \&Suwena, K. R. 2014.Statistika.Singaraja :Graha Ilmu.

Widaningsih. 2011. Penerapan Metode Penggunaan Alat Peraga dengan Peta Konsep sebagai Upaya Meningkatkan Minat dan Prestasi Belajar IPA Biologi 
Pokok Bahasan Klasifikasi Makhluk Hidup Murid Kelas VII B Smpn 3 Godean". Skripsi tidak diterbitkan. Yogyakarta : UIN SunanKalijaga.

Sudjana, N \& Rivai. 2002. Media Pengajaran. Bandung: Sinar Baru Algensindo

Sudjana, Nana. 2006. Penilaian Hasil Proses Belajar Mengajar. Bandung. PT RemajaRosdakarya.

Tiro, A. 1999. Dasar-dasar Statistik, Ujung Pandang: universitas Makassar.

Tim Penyusun. 2016. Pedoman Penulisan Skripsi. Makassar: FKIP Unismuh Makassar.

Tanjung Nur Bahdin dan H. Ardial. 2008. Pedoman penulisan Karya Tulis Ilmiah. Jakarta: Kencana. 